Source Analysis of the Crandall Canyon, Utah, Mine Collapse

D. S. Dreger, S. R. Ford, W. R. Walter

February 29, 2008

Science 
This document was prepared as an account of work sponsored by an agency of the United States government. Neither the United States government nor Lawrence Livermore National Security, LLC, nor any of their employees makes any warranty, expressed or implied, or assumes any legal liability or responsibility for the accuracy, completeness, or usefulness of any information, apparatus, product, or process disclosed, or represents that its use would not infringe privately owned rights. Reference herein to any specific commercial product, process, or service by trade name, trademark, manufacturer, or otherwise does not necessarily constitute or imply its endorsement, recommendation, or favoring by the United States government or Lawrence Livermore National Security, LLC. The views and opinions of authors expressed herein do not necessarily state or reflect those of the United States government or Lawrence Livermore National Security, LLC, and shall not be used for advertising or product endorsement purposes. 


\title{
Source Analysis of the Crandall Canyon, Utah, Mine Collapse
}

\author{
Douglas S. Dreger ${ }^{1}$, Sean R. Ford ${ }^{1,2}$ and William R. Walter ${ }^{2}$
}

Analysis of seismograms from a magnitude 3.9 seismic event on August 6, 2007 in central Utah reveals an anomalous radiation pattern that is contrary to that expected for a tectonic earthquake, and which is dominated by an implosive component. The results show the seismic event is best modeled as a shallow underground collapse. Interestingly, large transverse surface waves require a smaller additional non-collapse source component that represents either faulting in the rocks above the mine workings or deformation of the medium surrounding the mine.

1. Berkeley Seismological Laboratory

\section{Lawrence Livermore National Laboratory}

To whom correspondence should be addressed. Email: $\underline{\text { dreger@seismo.berkeley.edu }}$

On August 6, 2007 a magnitude 3.9 seismic event was associated with the tragic collapse of a Utah coal mine, which ultimately killed six miners and three rescue workers. The event was recorded on the local network of the University of Utah Seismic Stations (UUSS) and the Advanced National Seismic System (ANSS) operated by the USGS. In addition, the NSF Earthscope USAarray stations had just been installed in Utah in the months prior (www.earthscope.org). These stations provided unprecedented coverage (Fig. 1a) of a seismic source of this type. Analysis of the recorded seismograms reveals a 
very shallow depth and an anomalous radiation pattern, both of which are contrary to what is expected for a tectonic earthquake.

First motion polarities from vertical-component records of the seismic event associated with the collapse reveals that all are initially down, or dilatational, indicative of an implosional source (1). Consistent with this observation, the moment tensor inversion of complete, three-component, low-frequency $(0.02$ to $0.10 \mathrm{~Hz})$ ground displacement records recovers a mechanism that is most consistent with the gravity driven vertical collapse of a horizontally oriented underground cavity at a shallow depth consistent with the mine workings (Fig. 1b). The total seismic moment of this mechanism is $1.91 \times 10^{15}$ $\mathrm{N}-\mathrm{m}\left(M_{\mathrm{W}} 4.2\right)$. However, a pure vertically closing horizontal crack theoretically has no Love wave excitation and in order to explain the large amplitude Love surface waves observed on the tangential component (Fig. 1c) the mechanism must contain a non-crack component that is $24 \%$ of the dominant vertical collapse component $\left(1.71 \times 10^{15} \mathrm{~N}-\mathrm{m}\right)$.. The secondary source excitation of the moment tensor can be represented in multiple ways as the moment tensor decomposition is non-unique (2). Plausible interpretations of the secondary source include additional vertical dip-slip faulting, horizontal shear, nonuniform crack closure, and elastic relaxation in response to the mine collapse (3). The full moment tensor solution produces a pure dilatational P-wave first-motion mechanism consistent with the P-wave polarity observations.

The source-type diagram (4) in Fig. 1b illustrates the deviation from a pure earthquake double-couple (DC) source at the center in terms of a volumetric component (explosion 
or implosion) on the ordinate, and deviatoric component in terms of a volume compensated linear vector dipole (CLVD) on the abscissa. The moment tensor solution for the August 6, 2007 event plots in the region of a negative or closing crack. The diagram shows that despite the secondary source component the seismic waveforms are best fit by a model that is primarily comprised of a vertically closing horizontal crack, or underground collapse, and is similar to solutions obtained for other mine and Nevada Test Site (NTS) cavity collapses $(5,6)$. In contrast, NTS nuclear explosions modeled with the same method plot squarely in the explosion region of the diagram. Both the explosions and collapses are significantly separated from the population of earthquakes, which locate in the center of the diagram. Deviation from pure DC mechanisms in the earthquake population can be due to several factors including complex faulting, noise, and the effect of approximate Earth structure models to compute the basis Green's functions for the inversion. Despite the scatter within the three source populations, there is clear separation between each, indicating that regional distance seismic moment tensor methods are capable of source-type discrimination.

Our findings show that the seismic waveforms associated with the mine collapse are to first order due to the collapse, however the seismic source process was more complex than observed in other collapse events $(5,6)$ with a large secondary source generating strong Love waves. The findings further show that the application of seismic moment tensor analysis to non-tectonic seismic events such as buried explosions or underground collapses as illustrated here, demonstrates the feasibility of continuous monitoring of regional distance seismic wavefields for source-type identification beneficial for nuclear 
explosion monitoring and given rapid access to the seismic waveform data, the possibility of mining related emergency response applications.

\section{References and Notes}

1. Pechmann, J. C., submitted abstract to the 2007 Annual Meeting of the American Geophysical Union, 2007.

2. Jost, M. L. \& Herrmann, R. B., Seismol. Res. Lett., 60(2), 37-57, 1989.

3. Ford, S., D. Dreger, and W. Walter, SRL in preparation, 2008.

4. Hudson, J. A., R. G. Pearce, R. G., and R. M. Rogers, J. Geophys. Res. 9: 765-774, 1989.

5. Pechmann, J. C., W. R. Walter, S. J. Nava, and W. J. Arabasz, Seism. Res. Lett., 66, 25-34, 1995.

6. Ford, S., D. Dreger and W. Walter, Proceedings of the Monitoring Research Review, September 25-27, 2007, National Nuclear Security Administration, https://www.nemre.nnsa.doe.gov/prod/researchreview/2007/PAPERS/03-06.PDF, 2007.

7. D. S. Dreger and S.R. Ford are at the University of California, Berkeley, Berkeley Seismological Laboratory, and W. R. Walter is at Lawrence Livermore National Laboratory. Portions of this work were prepared by LLNL under Contract DE-AC5207NA27344. This is LLNL contribution UCRL-JRNL-235297. 


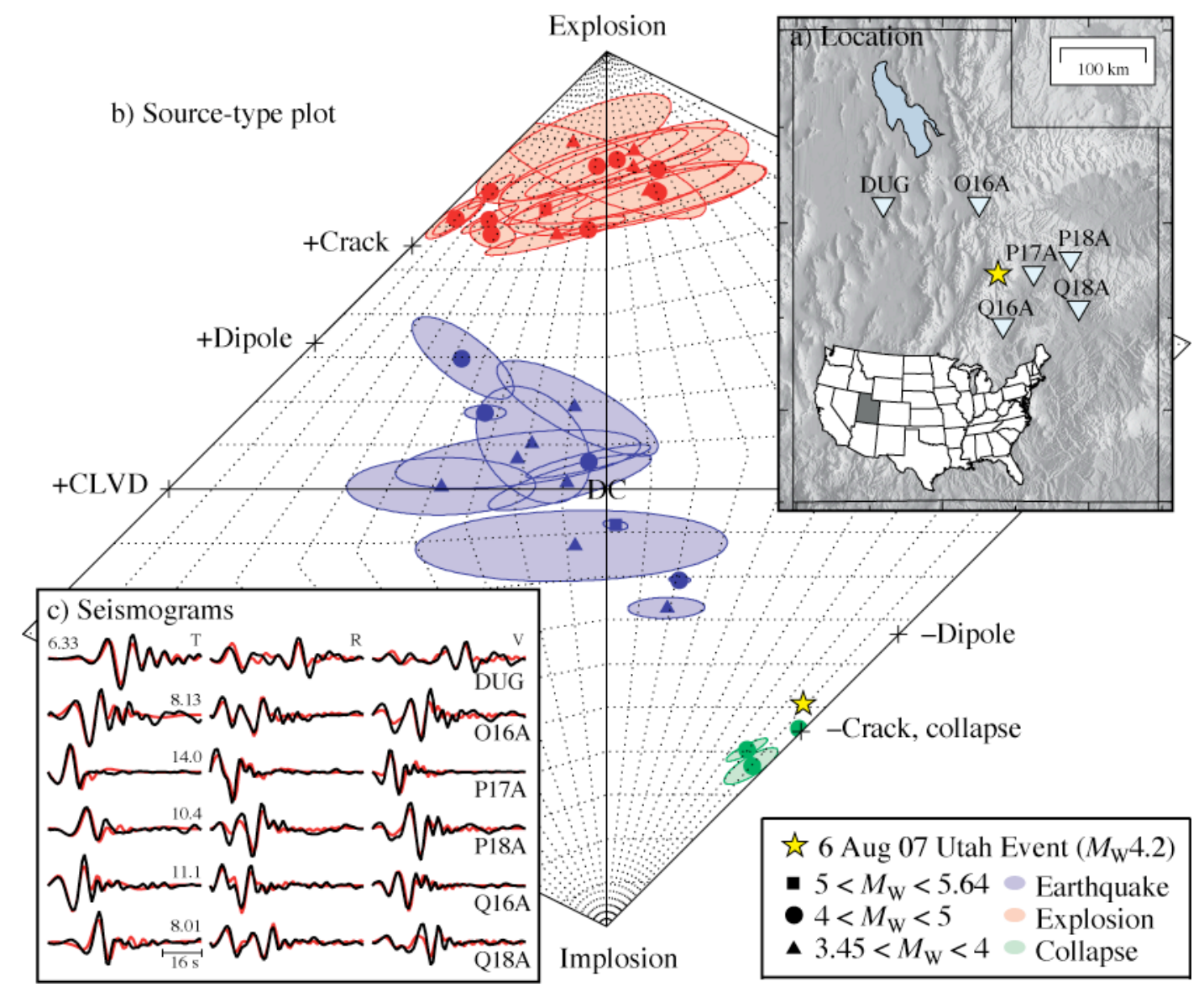

Fig 1. a) Locations of the August 6, 2007 event and 6 of the closest USArray and ANSS stations. b) Source type plot from the method of (3) shows clear separation of populations of earthquakes, explosions and collapses. The yellow star shows the solution for the August 6, 2007 seismic event. c) Observed seismograms (black) are compared to synthetics (red) for the non-double-couple solution, which is dominated by a horizontal closing crack (b). The maximum displacement $\left(10^{-7} \mathrm{~m}\right)$ of each set of tangential $(\mathrm{T})$, radial $(\mathrm{R})$, and vertical $(\mathrm{V})$ observations is given. 